Legal

\title{
Shaken baby syndrome
}

\section{P G Richards, G E Bertocci, R E Bonshek, P L Giangrande, $R$ M Gregson, T Jaspan, C Jenny, N Klein, W Lawler, M Peters, L B Rorke-Adams, H Vyas, A Wade}

\section{Before the Court of Appeal}

O ver three weeks in June 2005 , the Court of Appeal in London heard four appeals against convictions for non-accidental injury of infants: one murder, two manslaughter, and one grievous bodily harm. The three appeal judges delivered their judgement in a 67 page document on 21 July. ${ }^{1}$ Two appeals were upheld on the grounds of process, not medical evidence, one was dismissed, and in the fourth the conviction was reduced from murder to manslaughter.

The basis of the appeals was that since these convictions in the 1990s and 2000, new research had suggested that the long held belief that infants who presented with encephalopathy, thin subdural haemorrhages, and retinal haemorrhagesthe triad indicating "shaken baby syndrome" - had been subjected to extreme and repeated violence was wrong and that little or no trauma need be involved.

The research in question has become variously known since its publication in 2003 as the "Geddes hypothesis" or the "unified hypothesis". ${ }^{2}$ It was based on a pathological study of the dura of 50 intrauterine, neonatal, or infant deaths, which identified microscopic haemorrhage within the layers of the dura in 36. This led to the speculation that subdural and retinal haemorrhage was not caused by traumatic shearing of subdural veins and retinal vessels but by a combination of cerebral hypoxia, raised intra-cranial pressure from brain swelling, raised arterial pressure, and raised central venous pressure. The publication of this research was met with considerable scepticism by most working in the field of paediatrics, paediatric pathology, and paediatric head injury, ${ }^{3-7}$ but it was enthusiastically embraced by a few ${ }^{8} 9$ and regularly used in court proceedings.

The appeals therefore initially centred on examining in detail the Geddes hypothesis. Experts from the fields of biomechanics, haematology, infectious diseases, intensive care, neurosurgery, ophthalmology, paediatrics, neuroradiology, pathology, and statistics provided written evidence subject to cross examination for both the Appellants and the Crown. Early on in the proceedings it became clear that the Geddes hypothesis could no longer stand scrutiny. Under cross examination Dr Geddes accepted that the hypothesis was meant to stimulate debate and not to be taken as fact, and she stated that she would be very unhappy to think that cases were being thrown out on the basis that her hypothesis was fact. ${ }^{10}$ Dr Geddes accepted that the hypothesis was inconsistent with the lack of subdural and retinal haemorrhages seen in the majority of clinical circumstances in which sudden rises in central venous pressure and intra-cranial pressure occur in the context of acute severe hypoxia and raised or unstable arterial pressures, such as strangling and drowning. Dr Geddes indicated that she was now working on a further hypothesis but was unable to indicate when it was likely to be published. In their written judgement their Lordships clearly stated: "In our judgement, it follows that the unified hypothesis can no longer be regarded as a credible or alternative cause of the triad of injuries". ${ }^{11}$

With the Geddes hypothesis dismissed, attention turned to the minimal force required to injure an infant. All involved accepted that this was unknown, and because tests on live humans could not be carried out, would never be known for certain. All methods of estimating force, including biomechanical study, animal research, and clinical comparison with other forms of injury were, to some extent, incomplete and not fully applicable to human infants. Earlier research by Dr Geddes had focused on damage caused to the cardio-respiratory centres at the cranio-cervical junction, especially vulnerable as the fulcrum of movement of the relatively large infant head, and suggested that repeated extremely violent force may not be necessary to cause severe or fatal injury. ${ }^{12}{ }^{13}$ There was widespread acceptance by most experts involved that excessive trauma to the upper cervical cord could cause serious injury, but that normal or rough handling was very unlikely to do so. Most experts also accepted that if everyday accidents caused these findings, such cases would be extremely common instead of quite rare. As their Lordships stated: "In our view this points to the fact that cases of serious injuries caused by very minor force such as might occur in normal handling or rough handling of an infant, are likely to be rare or even extremely rare" ${ }^{14}$

With these general principles established, each of the four appeals was subject to detailed individual review. In two cases the appeals against the convictions of unlawful killing were dismissed. One was a conviction for manslaughter, but in another where the conviction was for murder, the acceptance that the event was likely to have been the result of loss of control rather than a premeditated act led to a reduction of the conviction to manslaughter. ${ }^{15}$ Two appeals were upheld largely on the basis of presentation of the medical evidence at the original trials rather than medical facts. In one case experts for the Appellant argued that there were other circumstances which might have combined to explain the infant's death, while the Crown's experts argued that the possible explanations were fanciful. Their Lordships concluded that had the Appellant's evidence been put before the jury it may have influenced the outcome and hence they upheld the appeal. ${ }^{16}$ In the other case where the appeal was upheld an infant suffered severe injuries from what was said to be a fall from a low height. Most experts from both sides and the three judges concluded that there were six separate sites of impact to the head, and yet, at the original trial, the Crown's case was of shaking alone, with no mention of impact. The defence therefore had no opportunity to answer the question of impact, and hence the appeal was upheld. ${ }^{17}$

So where does this leave the "shaken baby syndrome"? The triad of encephalopathy, subdural haemorrhages, and retinal haemorrhages as an indicator of head injury has stood the test of time and it has not been undermined by these proceedings. Furthermore, nontraumatic causes of this combination of injuries are, at most, extremely rare. However, doctors have been reminded that they need to consider the whole picture and not treat the triad alone as diagnostic. ${ }^{18}$ Careful imaging with plain $x$ ray, CT and MRI scanning, and a thorough search for infectious, metabolic, and haematological causes of each individual component of the triad need to be carried out. When they have been excluded the only remaining known cause for the triad is injury (whether shaking, impact, or a combination of both), and the minimal force required to cause injury is substantial. Their Lordships were of the opinion that such injuries could be caused by a single episode of ill-temper and loss of selfcontrol on the part of an adult, rather than always being due to repeated, purposeful, violent actions. Perhaps of greatest value may be to abandon the 
term "shaken baby syndrome". In any other age group an unexplained encephalopathy and haemorrhage into the subarachnoid and subdural spaces would be labelled "head injury" and the same features with long bone and rib fractures would be labelled "multiple injury". In these circumstances it is the responsibility of the authorities, not the doctors, to investigate how the injuries occurred, and the separation of the therapeutic and investigative aspects of the condition may be advantageous to all. However, doctors must continue to do their duty to report suspected abuse and to perform carefully documented medical investigation in cases of suspected child abuse.

Arch Dis Child 2006;91:205-206.

doi: 10.1136/adc.2005.090761

\section{Authors' affiliations}

P G Richards, P L Giangrande, Oxford

Radcliffe Hospitals, Oxford, UK

G E Bertocci, University of Pittsburgh, PA, USA

R E Bonshek, University of Manchester,

Manchester, UK

R M Gregson, T Jaspan, H Vyas, Queens

Medical Centre, Nottingham, UK

C Jenny, Brown University, Providence, RI, USA

N Klein, M Peters, Great Ormond Street

Hospital, London, UK

W Lawler, Forensic Pathologist, UK

L B Rorke-Adams, Children's Hospital of

Philadelphia, PA, USA

A Wade, University College, London, UK

Correspondence to: Dr P G Richards, Oxford Radcliffe Hospitals, Oxford, UK; peter. richards@orh.nhs.uk
Competing interests: all the authors gave evidence to the Court of Appeal following requests by the Crown Prosecution Service to review the four cases from their individual specialist perspectives

All the authors studied all cases involved in the appeals and wrote reports which were presented to the Court. The majority heard all the evidence presented and all have studied the judgement. The corresponding author wrote the basic manuscript which was re-drafted several times following comments and suggestions from the listed authors. All authors have read the final manuscript and agree with its contents.

\section{REFERENCES}

1 Supreme Court of Judicature Court of Appeal (Criminal Division). Neutral Citation Number: [2005] EWCA Crim 1980. Case Nos: 200403277, 200406902, 200405573, 200302848, Approved Judgement.

2 Geddes J, Tasker R, Hackshaw A, et al. Dural haemorrhage in non-traumatic infant deaths: does it explain the bleeding in "shaken baby syndrome" ? Neuropathol Appl Neurobiol 2003;29:14-22.

3 Punt J, Bonshek RE, Jaspan T, et al. The "unified hypothesis" of Geddes et al is not supported by the data. Pediatric Rehabilitation 2004;7:173-84.

4 Harding B, Risden RA, Krouch AF. Shaken baby syndrome. BMJ 2004;328:720-1.

5 Block RW. Fillers [letter]. Pediatrics 2004;113:432.

6 Lucey JF. Fillers [letter]. Pediatrics 2004; 113:432-3.

7 Smith C, Bell JE, Keeling JW, et al. Dural haemorrhage in non-traumatic infant deaths: does it explain the bleeding in "shaken baby syndrome" ? Geddes JE et al. A response. Neuropathol Appl Neurobiol 2003;29:411-13.

8 LeFanu J, Edwards-Brown R. Subdural and retinal haemorrhages are not necessarily signs of abuse [letter]. BMJ 2004;328:767.

9 Miller M, Leetsma J, Carlstrom T. A sojourn in the abyss: hypothesis, theory and established truth in infant head injury [letter]. Pediatrics 2004; 114:326.

10 Supreme Court of Judicature Court of Appeal (Criminal Division). Neutral Citation Number: [2005] EWCA Crim 1980. Case Nos: 200403277, 200406902, 200405573, 200302848, Approved Judgement. Paragraph 58.

11 Supreme Court of Judicature Court of Appeal (Criminal Division). Neutral Citation Number: [2005] EWCA Crim 1980. Case Nos: 200403277, 200406902, 200405573, 200302848, Approved Judgement. Paragraphs $68,69$.

12 Geddes JF, Hackshaw AK, Vowles GH, et al. Neuropathology of inflicted head injury in children. I. Patterns of brain damage. Brain 2001;124:1290-8.

13 Geddes JF, Vowles GH, Hackshaw AK, et al. Neuropathology of inflicted head injury in children. II. Microscopic brain injury in infants. Brain 2001;124:1299-306.

14 Supreme Court of Judicature Court of Appeal (Criminal Division). Neutral Citation Number: [2005] EWCA Crim 1980. Case Nos: 200403277, 200406902, 200405573, 200302848, Approved Judgement. Paragraphs 78, 79 .

15 Supreme Court of Judicature Court of Appeal (Criminal Division). Neutral Citation Number: [2005] EWCA Crim 1980. Case Nos: 200403277, 200406902, 200405573, 200302848, Approved Judgement. Paragraph 184.

16 Supreme Court of Judicature Court of Appeal (Criminal Division). Neutral Citation Number: [2005] EWCA Crim 1980. Case Nos: 200403277, 200406902, 200405573, 200302848, Approved Judgement. Paragraphs 151-3.

17 Supreme Court of Judicature Court of Appeal (Criminal Division). Neutral Citation Number: [2005] EWCA Crim 1980. Case Nos: 200403277, 200406902, 200405573, 200302848, Approved Judgement. Paragraphs 265,266 .

18 Supreme Court of Judicature Court of Appeal (Criminal Division). Neutral Citation Number: [2005] EWCA Crim 1980. Case Nos: 200403277, 200406902, 200405573 200302848, Approved Judgement. Paragraphs 69,70 .

\section{Preventing misdiagnosis of epilepsy}

\section{D Ferrie}

\section{Commentary on the papers by Hindley et al (see page 214) and Uldall et al (see page 219)}

o has become axiomatic that the rate of misdiagnosis of epilepsy is high. A population based study mainly in adults found a misdiagnosis rate of $23 \%,{ }^{1}$ while $26 \%$ of subjects referred to a single adult neurologist with "refractory epilepsy" were found not to have epilepsy. ${ }^{2}$ Hitherto, hard data in children on this has been lacking. Two studies in this month's Archives address aspects of this from different perspectives. Hindley et al report an eight year prospective study of the diagnoses made in children referred to a secondary level "fits, faints, and funny turns" clinic in Bury, UK. ${ }^{3}$ Uldall et al report a retrospective study of the final diagnosis compared to the referral diagnosis of 223 children admitted during 1997 to the Danish Epilepsy Centre which takes referrals from the whole of Denmark. ${ }^{4}$

Hindley et al found that epilepsy was the diagnosis in only $23 \%$ of the children referred. ${ }^{3}$ The largest diagnostic group was syncope of various sorts $(42 \%)$. Other relatively common diagnoses were psychological non-epileptic events (8\%), daydreaming $(5 \%)$, night terrors $(4 \%)$, migraine $(3 \%)$, benign paroxysmal vertigo $(2 \%)$, ritualistic movements, including gratification $(2 \%)$, and parental anxiety/fabricated illness (2\%). A miscellany of other conditions, including paroxysmal movement disorders, accounted for $8 \%$ of diagnoses. Fourteen per cent of patients remained undiagnosed. Unfortunately, the paper does not give referral diagnoses. It would be disingenuous to suggest that epilepsy was the preferred (or even likely) referral diagnosis in all. However, it is probable that it was suspected in many of those subsequently found not to have epilepsy.

Uldall et al found that 39\% of those referred to the Danish Epilepsy Centre did not have epilepsy. ${ }^{4}$ In $17 \%$ of referrals the reason for referral included concern that the diagnosis might not be epilepsy. However, even in those in whom the diagnosis of epilepsy was not in doubt at the time of referral, 30\% were subsequently "undiagnosed". 